\title{
Is a stimulus associated with the escape from shock a positive or negative reinforcer? Study I'
}

DOUGLAS WAHLSTEN AND MICHAEL COLE, UNIVERSITY OF CALIFORNIA, IRVINE EDMUND FANTINO, YALE UNIVERSITY

Rats failed to learn a new (bar press) response to either enter or leave a safe box which had been associated with the offset of shock. However, once the door between the boxes was open, those same rats ran faster leaving the safe box than entering it.

Beck (1961) pointed out that many studies indicating positive secondary reinforcement caused by shock termination were confounded by a failure to control for response elicitation. A satisfactory demonstration of secondary reinforcement would require the performance of a different response in the absence of the eliciting cues of the safe chamber. None of the recent findings supporting secondary reinforcement based on shock offset have satisfied this strong requirement for the existence of a secondary reinforcer.

Another problem restricting the interpretation of previous positive findings is that the effects were obtained at only one level of shock reduction. Since the strength of secondary reinforcement established with a positive primary reinforcer is generally found to increase with greater amounts of reward (Butter \& Thomas, 1958), when a negative primary reinforcer is employed, the amount of reward should be related to the magnitude of the shock which is reduced (Campbell \& Kraeling, 1953).

The present experiment was designed to evaluate two factors presumed to be important for establishing a positive reinforcer by pairing a neutral stimulus with reduction of noxious stimulation: (1) elicitation vs reinforcement of the response in testing; (2) the degree of aversiveness of the shock conditions during training. The Ss were required to learn a new response, bar pressing, to gain access to either the "safe" chamber or a "neutral" chamber during testing, thereby meeting the strong criterion of a secondary reinforcer. Aversiveness was evaluated by submitting independent groups to two different training conditions.

\section{Method}

The Ss were 10 male Sprague-Dawley albino rats, 350-500 $\mathrm{g}$, which had been used in a probability learning study with food reward.

The apparatus consisted of an alley divided into three chambers: a shock chamber, a "safe" chamber, and a "neutral" chamber. The chambers were separated by two motor-operated guillotine doors. The inside of the shock chamber was painted black except for its floor, which was a grid of $1 / 8 \mathrm{in}$. steel bars $1 / 2 \mathrm{in}$. apart, resting on a microswitch. The safe chamber had white sides, top, and doors; its floor was made of white burlap cloth and also rested on a microswitch. The neutral chamber had gray walls, top, floor, and door; 5 in. from the door and 1 in. above the wooden floor was a photocell. Both the safe and neutral chambers had an opening for a microswitch bar 2 in. above the floor and 2-1/2 in. from the door separating them.

The shock source was $650 \mathrm{~V}$ ac through a high resistance to give a constant current shock of either 1.0 or $0.4 \mathrm{~mA}$. The current was discontinuous, occurring in $300 \mathrm{msec}$ pulses, 100 per min, and was applied so adjacent bars were of opposite polarity.

There were two different training procedures. Four days of training plus testing were followed by three days of testing-only for Ss in both conditions. Training procedure $H$ (high aversiveness) was as follows: After the $S$ had been in the shock chamber $10 \mathrm{sec}$, a $1.0 \mathrm{~mA}$ shock came on for $5 \mathrm{sec}$, at which time the door was raised and $S$ escaped into the safe chamber. After remaining there for approximately $15 \mathrm{sec}, \mathrm{S}$ was returned to the carrying cage for $15 \mathrm{sec}$, and then the entire process was repeated. This continued for 25 trials on each of four training days for Group $H$. Training procedure $L$ (low aversiveness) was similar to $H$, but the parameters were .4 $\mathrm{mA}$ shock, 2 sec shock, and $30 \mathrm{sec}$ in safe chamber. In addition, the training during each of the four training days for Group L consisted of 10 shock trials interspersed with $1030 \mathrm{sec}$ adaptation trials in the neutral chamber, the order of trials being counterbalanced.

The $\mathrm{S}$ was tested using the safe and neutral chambers each day immediately following the training trials. During testing, $S$ was required to press a bar in one chamber in order to gain access to the opposite chamber. The $S$ was then free to run into that chamber. Half of the trials started from the safe chamber and half from the neutral one. Latencies were measured for bar pressing and for running to the opposite side following the raising of the door. If $S$ failed to press within $60 \mathrm{sec}$, the door was opened manually. A $60 \mathrm{sec}$ limit was also imposed upon running time. On the first four days, when the training regime was in effect, the Ss were given a counterbalanced order of 10 test trials, five starting in each compartment. For the three days following training, there were no shock trials and 20 such test trials.

\section{Resulis and Discussion}

For each $\mathrm{S}$ the $\log$ median latency on each day was found for pressing and crossing when Sstarted in either 
the safe or neutral chamber on test trials. Using training Days 2-4 and testing-only Days 1-3, an analysis of variance was done separately for bar pressing and for crossing latencies using a 3 by 2 by 2 by 2 factorial design, the factors being Days by Phase (training or testing -only trials) by Start Box (starting from safe or neutral chamber) by Aversiveness in training (high or low).

The long bar pressing latencies for all groups suggested that little pressing occurred under any condition; in fact, a press within $60 \mathrm{sec}$ only happened on about half the trials. There were no differential effects for Start Box or Aversiveness.

The mean crossing scores by days are shown in Fig. 1 and Fig. 2 for Groups $H$ and $L$ respectively. The only significant main effect was for Start Box $(F=10.34$, df $=1 / 8, p<.05$ ); running was faster leaving the safe box than entering it. As is obvious from the graphs, the effect of Start Box was greater for $H$ than $L(F=7.56$, $\mathrm{df}=1 / 8, \mathrm{p}<.05)$. Also interacting with Start Box was the Phase factor $(F=12.86, d f=1 / 8, p<.01)$; the differences were smaller on days with no shock trials. The magnitude of this difference was greater for the $L$ than the $H$ group $(F=5.64, d f=1 / 8, p<.05)$.

Of particular interest was the comparison of Start Box effects during the testing-only days for $\mathrm{H}$ and $\mathrm{L}$. Clearly the H Ss maintained a much faster speed leav-

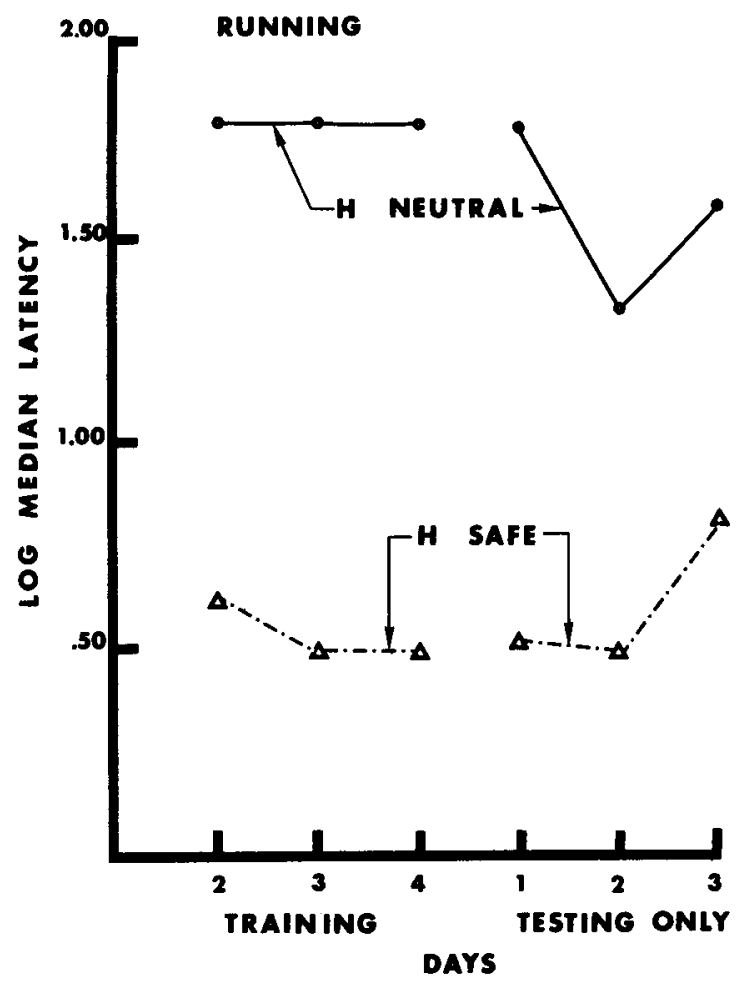

Fig. 1. Transformed latencies for running from safe and neutral boxes for Group $H$ (high aversiveness).

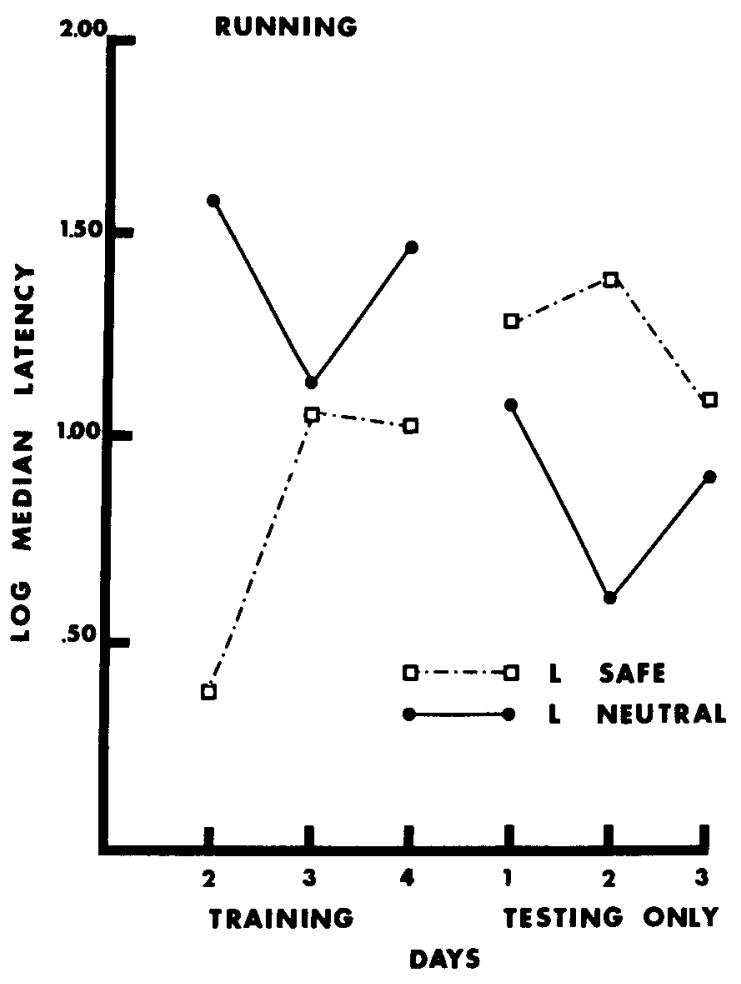

Fig. 2. Transformed latencies tor running from safe and neutral boxes for Group L (low aversiveness).

ing the safe box, whereas L Ss actually ran faster into the safe box, this latter difference being marginally significant $(F=4.25$, df $=1 / 16, p<.10)$. However, in an initial preference test, every S spent more time in the safe box than in the neutral box. This suggested that a definite preference existed for the safe box prior to training.

Taken as a whole, these results provide no support for the hypothesis that stimuli associated with termination of shock can become positively reinforcing or even eliciting. A conclusion more consistent with our finding would be that the safe chamber is aversive during training and that this aversiveness extinguishes in the absence of shock.

\section{References}

Beck, R. C. On secondary reinforcement and shock termination. Psychol. Bull., 1961, 58, 28-45.

Butter, C. M., \& Thomas, D. R. Secondary reinforcement as a function of the amount of primary reinforcement. J. comp. physiol. Psychol., 1958, 51, 346-348.

Campbell, B. A., \& Kraeling, D. Response strength as a function of drive level and amount of drive reduction. J. exp. Psychol., $1953,45,97-101$.

\section{Note}

1. Research supported by NIH Grant MH11180-01 to Michael Cole and NSF Grant NSFGB-3626 to Edmund Fantino. The authors are grateful to Sally Brown for assistance in collecting these data. 